\title{
Neonatal Land Transport
}

\author{
Aleksandra Doronjski*, Vesna Stojanovic, Slobodan Spasojevic, Nenad Barisic \\ Medical Faculty, University in Novi Sad, Serbia
}

Submission: October 04, 2016; Published: January 24, 2017

*Corresponding author: Aleksandra Doronjski, Medical Faculty, University in Novi Sad, Institute for Children and Youth Health Care of Vojvodina Novi Sad, Vojvodjanskih brigada 12, 21000 Novi Sad, Serbia. Email: adoronjski@yahoo.co.uk

\section{Summary}

Owing to good perinatal care (prenatal detection of problems and timely transport of pregnant women), critically ill newborns are usually delivered in large centres (with tertiary perinatal care provided) where they can be given intensive care and therapy. When this is not the case, a critically ill newborn must be transported to a centre with a higher level of perinatal care. The less time it takes from identifying a problem to transpor to a higher level centre, the better the chances for a better outcome, even though the transport of newborns is still tied to higher morbidity and mortality rates than in utero transport. This is especially the case with extremely preterm and very preterm neonates.

The successful medical transport of such high-risk and sensitive population requires a highly specialized personnel and appropriate equipment. In ideal conditions, the neonatal transport team is a link in the system of neonatal care followed by an intensive care unit where critically ill newborns are treated (with the right personnel, equipment and subspecialists for diagnostics and therapy when needed).

The composition of transport teams varies according to the transport type (by land, air or water) and referral organization (one way, two ways, medical teams specialized in neonatal transport); however, education, competence and equipment including the necessary medical supplies should be appropriate for the level of care. Also, basic stabilization measures before transport and the necessary medical and technical procedures before and during transport are the same in all the types of transport mentioned. Special procedures (administration of surfactants, 'cooling', administration of prostaglandins) should be performed by an experienced team well familiar with the application techniques, monitoring methods and possible complications (and how to deal with them).

The peculiarity of neonatal transport are surgical patients with congenital anomalies who require specific procedures (such as gastric emptying, ventilation, certain body positioning etc). Any transfer, as well as any medical procedure should be properly documented (pretransport documentation, newborn's condition at the transport team arrival, performed interventions, the course of transport, any complications, transport time etc).

Assessing the right transport indications, maintenance of competence and keeping the transport team properly equiped make neonatal transport a significant segment of operations of any healthcare facility.

\section{Introduction}

Away from the secure and well supplied neonatal intensive care unit (NICU), with special equipment and limited personnel, and often uncertain and unpredictable transport course, a transport team works in conditions far from ideal. During transport, a newborn is exposed to numerous harmful noxae - noise, vibrations, acceleration or deceleration, temperature instability, all of which could additionaly aggravate an already difficult condition. The treatment outcome of the transported newborn depends on a number of factors, some of which can be measured - acidosis levels, retained carbon dioxided levels, blood pressure, glucose in blood levels, and temperature. Maintaining the neonate's organism homeostasis is thus of vital importance, but sometimes very difficult to achieve during transport.
In view of all above mentioned factors, neonatal transport is a risk for a newborn as well as for a transport team [1-3]. The first transport incubator constructed for 'the care of weak and premature infants' was used in 1900 by Dr. Joseph De Lee (Chicago Lying-In Hospital). The incubator was used to transport 'these weak children from remote parts of town and suburbs' [4].

The regionalization of perinatal care in the entire world, which started during the 1970 's, contributed to the agglomeration of ill neonates in the centres that could provide diagnostics and treatment for most of neonatal diseases. Directly resulting from regionalization, the number of transports of critically ill neonates increased, to centres where they are taken care of and diagnostical and therapeutical procedures fully observed, either in utero, 
before birth (applying corticosteroids, for instance), or during and directly following birth (nCPAP, surfactant). Deregionalization that is under way in developed countries implies creation of intensive care units in various healthcare facilities (and ample investments into equipment and personnel) with staff training and highly developed transport network. The aim is to bring each and every newborn, should there be a need, to tertiary care with appropriate diagnostics and treatment.

Transport could elevate the risk of mortality and aggravate the newborn's illness. Ill neonates that are transported from a lower to a higher level centre of perinatal care usually have a less successful outcome that the ones born in a high level care centre; even the newborns that are transported between the same high level care centres have a worse outcome than the neonates that were not transported. This is the reason why, when assessing potential neonatal problems, in utero transport is the best solution $[1,2]$.

Even though regionalization, deregionalization and even grading of neonatal departments, that is a division of NICU into different categories (primary, secondary, tertiary) have been carried out, there is still a certain number of newborns in need of intensive care and therapy that are born in primary and secondary care settings. These are most often the reasons:

A. Unforeseen or unidentified perinatal circumstances that do not allow for the mother to be transported - no time for in utero transport;

B. Unidentified prenatal condition that is life threatening for a newborn;

C. The pregnant woman's (obstetrician's) wish to deliver the baby in a certain facility;

D. Some other reason;

E. Neonatal transport from secondary or tertiary care NICU to a higher level.

\section{Modes of Neonatal Transport}

Cocnerning the type of vehicle and other options, the transport can be made by land or air, and also on water. Transport vehicles used for land transport can be specialized emergency medical vehicles, rarely standard emergency medical vehicles with the addition of a mobile incubator; air transport implies the use of special aeroplanes and helicopters for the transport of patients, but standard aeroplanes and helicopters can be used as well with the additon of mobile incubators. Waterway transport makes use of vessels that can be fitted with an incubator. The advantages of land transport are as follows:
A. The lowest cost
B. Mostly not affected by the weather conditions
C. Better fitted to patients
D. Vehicles interior can be customized (dedicated exclusively to neonatal transport)

E. Land transport allows (with appropriate equipment) for the transport of several patients simultaneously (two mobile incubators).

Shortcomings of land transport are:

\section{A. Slowness}

B. The need to secure the incubator stability and to bring in all the necessary equipment (2).

Generally speaking, critically ill neonatal transport (apart from in utero transport and the so-called 'intra-hospital' transport, which are segments in their own right) can be organized as
A. two ways transport and
B. one way transport.

These two transport types (mostly) differ according to who organizes and who performs the transport:

A. Two ways transport: usually organized and carried out by a higher lever healthcare facility team. (It is a common practice that teams from facilities with IIIb or IIIc perinatal care levels organize two ways transport of critically ill newborns; the advantages are the presence of competent personnel, appropriate equipment and the immediate treatment).

B. One way transport: by a healthcare facility team organizing the transport into a facility of a higher level care. (In most cases, there is no specialized transport team, it is formed ad hoc with basic transport equipment).

C. By a specialized team for neonatal transport: this kind of transport is characteristic of countries with vast territories and small population (such as Australia), where the predominant mode of transport is by air. These teams are specially trained and supplied so they can start and administer therapy enroute [5].

D. By teams for emergency medical assistance who perform neonatal transport along their regular duties (critically ill neonatal transport occurs sporadically) without the presence of a neonatologist or specially trained neonatal transport physician on board.

\section{Two Ways Land Transport of Critically Ill Newborns}

To ensure timely, safe and beneficial transport, the following conditions should be met:

\section{A. Appropriate transport team composition;}

B. Required competencies and skills of transport team members ;

C. Required transport equipment:

D. Required drugs and medical supplies;

E. Accurately assessed transport indications;

F. Choosing the optimal time (newborn's age and condition) for transport. 
Concerning the composition of the critically ill neonatal transport team, its permanent members can be:

A. A physician, a nurse (compared to the modes of transport, physicians and nurses can be specially trained for neonatal transport or carrying out the transport by merely monitoring the patient).

B. A registered nurse, a respiratory therapist (This transport team composition is characteristic of countries where the costs of transport are very high if a physician is on board, so it is more cost effective having a respiratory therapist in the team - with a physician 'on line'.

C. A nurse (trained to monitor vital parameters and perform basic cardiopulmonary resuscitation (CPR), while consulting with a physician 'on line' in case of any other problems).

D. Driver (In some countries drivers are also trained nurses).

In the case of land transport, the physician makes the decision about the transport speed and whether to call for police escort in order to ensure undisturbed ride without speeding or slowing down. If the newborn is stabilized before transport, there is almost no need for high speed driving. If it is possible to plan transport ahead, it is best to avoid the time of traffic rush hour. Should the newborn's condition worsen during transport or a certain medical procedure must be performed (reintubation, tenting or mere auscultation), the transport vehicle should be stopped so that the procedure can be properly performed.

The transport of ill newborns is a demanding task which requires specific equipment and competencies; each transport should be planned so that the risk of complications en-route is minimized; it is much more difficult and involves higher risk to intervene during transport (intravenuous cannula insertion, endotracheal intubation) than performing these in a regional hospital. These are the reasons why certain conditions and procedures must be met before transport takes place $[6,7]$.

Condtions and procedures before transport:

\section{Stabilization of an Infant}

Before each transport, the condition of the newborn must be stabilized as much as possible and the therapy administered $[7,8]$. Then the following measures are $[5,9]$ :

\section{Respiratory stabilization}

Many diseases in newborns manifest through respiratory problems, even in cases when the primary disease is not respiratory. Neonatal respiratory reserves are relatively small and without adequate control respiratory problems may become significant. It is of vital importance to ensure enough oxygenation and ventilation (with appropriate pCO2) before transport. If there is a need for respiratory support by using nasal CPAP or for intubation and assisted ventilation, respiratory support should be provided in such a way that there is enough even in case of condition aggravation during the transport. If it is uncertain that the newborn will be able to breathe spontaneously, the infant should be intubed before transport and adequate ventilation secured. Whenever it is possible, acid-base status should be checked before transport.

\section{Circulatory stabilization}

Neonatal circulation is rather unstable and many diseases due to which the newborns are transported are accompanied by different digrees of circulatory insufficiency. This is especially the case with newborns having respiratory problems (Respiratory Distress Syndrome, Meconium Aspiration Syndrome), heart diseases and serious infections. Newborn's circulation state can be assessed by measuring arterial blood pressure. Invasive blood pressure measurement is the safest and most reliable option; it is also possible to use a cuff, but it is less reliable. It is compulsory to check the blood pressure values before transport and to compare them with normal values for that age and gestational age. The occurence of metabolic acidosis refers to circulatory insufficiency and must be treated before transport. Newborns with unstable circulation, who are given intravenous therapy or endotracheal intubation should have at least two vascular lines open [10].

\section{Temperature stabilization}

It is important for a newborn to have normal temperature before and during transport. Hypothermia will increase respiratory problems as well as the risk of other complications. Overheating, especially of asphyctic newborns may increase the risk of cerebral disease. (This is why therapeutic hypothermia is planned for before transport).

\section{Metabolic stabilization}

It is necessary to start with dextrose infusion before transport, and the enteral food should be evacuated (by emptying the stomach) in order to prevent aspiration of gastric contents during transport. Normal need for glucose is equal to the solution of $10 \%$ dextrose with the volume of $3,6 \mathrm{ml} / \mathrm{kg} / \mathrm{h}(6 \mathrm{mg} / \mathrm{kg} / \mathrm{min}$ glucose $)$.

\section{Stabilization of the Central Nervous System (CNS)}

Some severely ill newborns have convulsions. It is of vital interest to secure metabolic needs of CNS before transport, especially by avoiding hypoglycemia. It is necessary to stop the seizures prior to transport. Some authors report higher grade and frequency of ICH in transported neonates [11].

\section{Infection treatment}

At slightest suspicion, adequate antibiotics therapy should be administered prior to transport. Obtaining samples for microbiological analyses is beneficial before starting with antimicrobial therapy $[12,13]$.

\section{Surfactants administration prior and during transport}

Administration of surfactant prior the transport is safe. The newborn should be given time to stabilize after surfactant was administered. Administration of surfactant does not influence the 
frequency of transport of low birth weight neonates into centres with higher levels of care and treatments [14-17].

\section{Administration of prostaglandins during transport}

In spite of adverse effects of prostaglandins (hypotension, vasodilatation, redness, heart rhythm disorder, convulsions, apnea, hypoventilation, frequent bowel movement, diarrhoea, pyrexia), its administration is not contraindicated to most congenital heart defects (except for total anomalous pulmonary venous return). The recommendation for patients who are administered prostaglandins during transport is to be electively intubated for timely therapy of sudden apnea. Every facility should have its own protocol or prostaglandins administration during transport [1821].

\section{Cooling during transport}

Therapeutic hypothermia that is started within six hours after birth has as a result better neurodevelopmental outcomes at term neonates with moderately severe and severe Hypoxic Ischemic Encephalopathy. The largest number of these neonates are born in facilities where NICU are not properly equipped for cooling; with the addition of transport time, it is quite possible that therapy will start late, so that neuroprotective effect of cooling should be initiated even during transport, optionally by passive cooling. Every facility that transports neonates should have its own protocol on this procedure concerning the necessity of a systematic approach[22,23].

\section{Communication with regional facilities, medical documentation etc}

Prior to transpott a regional healthcare facility should be contacted to ensure stabilization of the newborn (especially in the case of surgical diseases, congenital defects, etc). One should obtain a list of the required documents to be given to the transport team (X-ray records, laboratory analyses results). It is important to note whether it is necessary for mother's blood to be taken [23].

\section{Transport team}

The required competencies (theoretical and skills) of the transport team members:

A. Physician: Beside theoretical knowledge of pediatricsneonatology and perinatology, they must be skilled at: nasogastric tube placement, catheterization of urinary bladder, rectal tube placement, peripheral venuous cannulation, central venuous cannulation (and of umbilical vein), endotracheal intubation, pleural space drainage, surfactant administration, application of respirator, aspirator and defibrillator. They should be excellent with techniques of manual ventilation and CPR. Beside theoretical and practical knowledge, they must be able to recognize and act immediately upon any change in the neonate's condition during transport as well as anticipate potential problems.

B. Nurse: Beside competence and skills, they are responsible for all the apparatus to be in working order, they must know in detail how to assemble all transport devices, check the contents of transport medical supplies (expendable supplies and drugs). They are skillful at performing CPR.

C. Driver: is responsible for the transport vehicle, gas and power supply to all machines and devices. They should be trained to repair any potential defects during transport and finds the best transport route (through rush hour, extreme weather conditions).

Necessary equipment

1. Mobile incubator with a transport ventilator

2. Device for the applicatin of nitric oxide

3. Portable ecmo

4. Cooling device

5. Oxygen hood

6. Monitor (ECG, respiratory, pCO2, p02)

7. Pulse oximeter

8. Body temperature measuring device

9. 02 concentration measuring device

10. Blood pressure measuring device (by cuff or artery blood pressure)

11. Reanimation balloon with masks (in different sizes)

12. Intubation equipment

13. Air way (different sizes)

14. Aspirator

15. Injectomats

16. Stethoscopes (for the physician and the nurse)

Before placing the equipment into the transport vehicle, it must be inspected. Its working order and contents are checked. Following the equipment, all connections are checked (power, medical gases) and their state of operation. Drugs and expendable medical supplies container is inspected before and after it was brought into the vehicle. All the equipment used during transport must be inspected and serviced timely and regularly. There has to be a nurse responsible for releasing/taking complete and working equipment. Medications that are prepared for transport have to be properly labeled and packed, and there has to be a person responsible for this. Transport equipment and applied medications and medical supplies should be recorded in their own documents.

If any device is not working properly, it should be detected in time, duly noted and repaired [23].

It is vital that transport team is very well familiar with monitoring equipment and ablr to manage in situations when this equipment is unreliable [12]. 
Medications that are required for transport (in appropriate solution, with precisely stated concentration, i.e. the amount of drug per unit of volume):

1. Adrenalin

2. Adenosine

3. Antibiotics

4. Aqua redestilata (pro injectione)

5. Bensedin

6. Calcium

7. Dexamethason

8. Dopamin

9. Dobutamin

10. Diuretics

11. Fentanyl

12. Flormidal (Midazolam)

13. Dextrose $10 \%, 5 \%, 12,5 \%, 50 \%$

14. Glucagone

15. Heparin

16. Hydrocortison

17. Konakion (vitamin $\mathrm{K}$ )

18. Lidocaine

19. $\mathrm{NaCl} 0,9 \%, \mathrm{NaCl} 3 \%$ normal saline, $3 \%$ saline

20. NaHCO3 8,4\% bicarbonate

21. Phenobarbiton

22. Prostaglandin

23. Surfactant

Expendable medical supplies required for the transport (plastic and suture material).

\section{Documentation}

Accurate and proper record keeping is an important segment of neonatal transport. If there is no possibility for a telephone conversations to be recorded - and even if there is, a written form should be filled, containing the following items [24-27]:

A. When, where from and who makes the call (name and surname of that person - physician or nurse)

B. General information about the patient to be transported (name and surname, sex, date and hour of birth, place of birth)

C. Discription of the disease along with therapy and diagnostic procedures results; current diagnosis

D. Assessment of the emergency of transport
E. Instructions to the caller - potential diagnostic and therapy procedures to be performed before the transport team arrives

F. Contact person's name and telephone number that transport team can contact if needed

G. Assessment of time from the moment of making the telephone call to the transport team's arrival (which is told to the person making the call).

Following the transport team arrival, the physician (or nurse) who had made the call (or treated the newborn until the transport team arrival) validates the medical documents stating the patient's condition by signing them when the team has arrived. It is useful to hand over to the transport team the copy of work-ups, $\mathrm{X}$ rays, blood type of the newborn and mother, important information about pregnancy - diseases, an antibody titer etc. Transport sheet should contain the name and surname of the physician, the nurse and the driver who carried out the transport $[9,11]$.

\section{Disinfection during transport}

Disinfection during transport is very important in order to prevent spreading multi-resistant germs from one facility to another.

\section{Parents' consent prior to transfer}

Prior to transport parents must be fully acquainted with the information of their child's condition and the purpose of transfer. With different congenital malformations it is important to explain to parents the type and kind of defect, the options of treatment and the risks. One should be very careful about giving prognosis concerning that transfer itself does not guarantee survival and healing. Parents should sign a written consent for the transport and special procedures (transfusion of blood products, or surgery if necessary) [28-30].

It is of great importance for parents to be able to see and touch their child, and if possible, take photographs or get the newborn's foot print before transport. If parents cannot be transported together with their newborn, the regional hospital is obliged to give them information about the place and possibilites of staying with their child (accommodation for mothers, a hotel etc).

Most NICU that newborns are transferred to have brochures with the information about the department, its address, telephone number, that should be given to parents before transport. Parents need to meet the people in charge of the transport (know the name and surname of the physician and nurse). If it is assessed that the newborn is critically ill with an unfavourable prognosis, the team may talk to parents about potential naming and christening the child, etc [31-33].

\section{Indications for Transport}

Regarding the digree of equipment and knowledge of physicians, the decision about the necessity of transport is based on the following [23]: 

A. How severe neonates' condition is;
B. Assessment of a potential aggravation;
C. The need for a certain special therapy procedure;
D. If a treatment and/or a therapy procedure is available only in a tertiary level facility.

\section{References}

1. Shenai JP (1977) Sound levels for neonates in transit. J Pediatr 90(5): 811-812.

2. Shenai JP, Johnson GE, Varney RV (1981) Mechanical vibration in neonatal transport. Pediatrics 68(1): 55-57.

3. MacFaul R, Werneke U (2001) Recent trends in hospital use by children in England. Arch Dis Child 85(3): 203-207.

4. Bryan L Ohning (2015) Transport of the Critically III Newborn.

5. Karlsen K (2011) The STABLE Program.

6. Butterfield LJ (1993) Historical perspectives of neonatal transport. Pediatr Clin North Am 40(2): 221-239.

7. Moving Intensive Care of Kids.

8. McCloskey K, Hackel A, Notterman D (1993) Guidelines for Air and Ground Transport. 146.

9. Latinović R, Bregun Doronjski A, Kovačević B, Konstantinidis G, Velisavljev G, et al. (1995) Mesto i uloga transporta ugroženog novorodjenčeta. I stručni sastanak Neonatologa Jugoslavije. Beograd. Zbornik 51-53.

10. McCloskey K, Orr R (1995) Pediatric Transport Medicine. 700.

11. Spasojević S, Stojanović V, Savić R, Doronjski A (2010) Intrakranijalno krvarenje i transport k sebi prevremeno rodjenog novorodjenčeta. Medicinski pregled 63(7-8): 454-458.

12. Ohning BL, Smith J, Pittard WB (1996) Monitoring of the Neonatal Patient: The Transport Environment. Neonatal Intensive Care 9(4): 3638.

13. Mears M, Chalmers S (2005) Neonatal pre-transport stabilisation caring for infants the STABLE way. Infant 1(1): 34-37.

14. Spasojević S, Doronjski A, Kovačević B, Pavlović V, Nikolić M (2007) Smernice za primenu preparata surfaktanta pre transporta. U: Radunović N, ur. Zbornik radova VI Kongresa perinatalne medicine Srbije i Crne Gore. Beograd, Srbija, 198-200.

15. Spasojević S, Konstantinidis G, Doronjski A (2010) Morbiditet i mortalitet prevremeno rođene novorođenčadi nakon započinjanja Nacionalnog programa in vitro fertilizacije - naše iskustvo. Srp Arh Celok Lek 138(1-2): 67-71.

16. Hohlagschwandtner M, Husslein P, Klebermass K, Weniger M, Nardi A, et al. (2001) Perinatal morbidity and mortality. Comparison between maternal transport, neonatal transport and inpatient antenatal transport. Arch Gynecol Obstet 265(3): 113-118.

17. Towers CV, Bonebrake R, Padilla G, Rumney P (2000) The effect of transport on the rate of severe intraventricular hemorrhage in very low birth weight infants. Obstet Gynecol 95(2): 291-295.

18. McGlone L, Jackson L (2006) Prostaglandin use in neonatal transport. Arch Dis Child Fetal Neonatal Ed. 91(5): F389.

19. Siu KL, Lee WH (2002) Use of Prostaglandin E2 in Neonatal Emergency Transport: A Case Report. HK J Paediatr (new series) 7: 223-226.

20. Meckler GD, Lowe C (2009) To Intubate or Not to Intubate? Transporting Infants on Prostaglandin E1. Pediatrics 123(1): e25-e30.

21. Shivananda S, Kirsh J, Whyte HE, Muthalally K, McNamara PJ (2010) Impact of Oxygen Saturation Targets and Oxygen Therapy during the Transport of Neonates with Clinically Suspected Congenital Heart Disease. Neonatology 97(2): 154-162.

22. Kendall GS, Kapetanakis A, Ratnavel N, Azzopardi D, Robertson NJ et al. (2010) Passive cooling for initiation of therapeutic hypothermia in neonatal encephalopathy. Arch Dis Child Fetal Neonatal Ed 95(6): F408-F412.

23. Woodward GA (2007) Guidelines for Air and Ground Transport of Neonatal and Pediatric Patients. $3^{\text {rd }}$ (edn). American Academy of Pediatrics Section on Transport Medicine, American Academy of Pediatrics, Elk Grove Village, Illinois, USA.

24. Spitz L,Wallis M,Graves HF (1984) Trasport of the surgical neonate. Arch Dis Child 59(3): 284-288.

25. Neonatal Transport Data System (2011) California Perinatal Transport System (CPeTS) Network Database. Managed by California Perinatal Quality Care Collaborative (CPQCC). Manual of Definitions For Infants Born 2011. Version 12.16. November 232010.

26. Arad I, Baras M, Bar-Oz B, Gofin R (2006) Neonatal transport of very low birth weight infants in Jerusalem: revisited. Isr Med Assoc J 8(7): 477-482.

27. Shenai JP (1977) Sound levels for neonates in transit. J Pediatr 90(5): 811-812.

28. Shenai JP, Johnson GE, Varney RV (1981) Mechanical vibration in neonatal transport. Pediatrics 68(1): 55-57.

29. MacFaul R, Werneke U (2001) Recent trends in hospital use by children in England. Arch Dis Child 85(3): 203-207.

30. Karlsen K (2001) The STABLE Program. Utah, USA.

31. Butterfield LJ (1993) Historical perspectives of neonatal transport. Pediatr Clin North Am 40(2): 221-239.

32. http://www.nets.org.au/About-NETS.aspx

33. Ohning BL, Smith J, Pittard WB (1996) Monitoring of the Neonatal Patient: The Transport Environment. Neonatal Intensive Care 9(4): 3638. 
(C) Commons Attribution 4.0 Licens BY DOI: 10.19080/AJPN.2017.02.555594

\section{Your next submission with Juniper Publishers will reach you the below assets}

- Quality Editorial service

- Swift Peer Review

- Reprints availability

- E-prints Service

- Manuscript Podcast for convenient understanding

- Global attainment for your research

- Manuscript accessibility in different formats

( Pdf, E-pub, Full Text, Audio)

- Unceasing customer service

Track the below URL for one-step submission https://juniperpublishers.com/online-submission.php 